\title{
Multivariate restricted maximum likelihood estimation of genetic parameters for production traits in three selected turkey strains
}

\author{
H Chapuis ${ }^{1,2}$, M Tixier-Boichard ${ }^{3}$, Y Delabrosse ${ }^{2}$, V Ducrocq ${ }^{1}$ \\ 1 Station de génétique quantitative et appliquée, Institut national \\ de la recherche agronomique, domaine de Vilvert, 78352 Jouy-en-Josas cedex; \\ ${ }^{2}$ Bétina Sélection, Le Beau Chêne, Trédion, 56250 Elven; \\ ${ }^{3}$ Laboratoire de génétique factorielle, Institut national de la recherche agronomique, \\ domaine de Vilvert, 78352 Jouy-en-Josas cedex, France
}

(Received 22 May 1995; accepted 5 December 1995)

\begin{abstract}
Summary - Genetic parameters related to growth, carcass composition and egg production were estimated on three (two female and one male) commercial strains of turkey using the method of restricted maximum likelihood (REML). In order to account for the sexual dimorphism in turkeys, body weight (BW, measured at 12 and 16 weeks of age) was considered as a sex-limited trait. As many as seven traits were analyzed simultaneously in one strain. Egg numbers were normalized using a Box-Cox transformation. Three different genetic models were used. The first one was a linear mixed model with a direct genetic effect. Model 2 accounted in addition for a dam's environmental effect, while model 3 introduced a maternal genetic effect. The heritability estimates of BW were very high, especially for female traits (0.77 for female BW16 and 0.68 for male BW16 in strain B). Sexual dimorphism was less heritable $(0.23,0.16$, and 0.14 for the 16 weeks body weight sex difference in the three strains considered). One of the female strains exhibited a strongly negative genetic correlation $(-0.5)$ between female BW and egg number. The elevated values of the estimates probably originated from the method used, which accounted for the bias due to the sequential selection that had been carried out, and from the choice of the base population. Use of models 2 and 3 resulted in slightly lower heritability estimates than model 1, due to low maternal effects. The latter, however, offered a reasonable compromise between quality and computational cost of the evaluations.
\end{abstract}

turkey / genetic parameter / restricted maximum likelihood

Résumé - Estimation par maximum de vraisemblance restreinte des paramètres génétiques de caractères de production dans trois souches de dinde. Les paramètres génétiques de caractères relatifs à la croissance (poids corporels à 12 et 16 semaines), la teneur en gras (mesure ultrasonique) et la ponte ont été estimés à l'aide de la méthode du maximum de la vraisemblance restreinte (REML) dans trois souches de dindes 
sélectionnées. Les caractères de poids ont été séparés selon les sexes, afin de rendre compte du dimorphisme sexuel important dans l'espèce et jusqu'à sept caractères ont ainsi été analysés simultanément dans une des souches. Les données de ponte ont été normalisées à l'aide d'une transformation de Box-Cox. Trois modèles génétiques différents ont été utilisés. Le premier est un modèle linéaire mixte incluant la valeur génétique additive individuelle comme effet aléatoire. Dans les autres on ajoute un effet maternel d'abord considéré comme un effet essentiellement de milieu (modèle 2) puis uniquemement génétique (modèle 3). Les héritabilités sont très fortes pour les poids corporels, plus élevées pour les poids femelles que pour les poids mâles (0,77 pour les femelles à 16 semaines dans la lignée $B$ contre 0,68 pour les mâles). Le dimorphisme sexuel est un caractère plus faiblement héritable $(0,23 ; 0,16$; et 0,14 pour la différence de poids entre mâles et femelles à 16 semaines dans les trois lignées). Dans une des lignées femelles, la corrélation génétique est fortement négative $(-0,5)$ entre le poids des femelles et le nombre d'œufs pondus. Les valeurs élevées des paramètres génétiques s'expliquent probablement par la méthode employée qui permet de prendre en compte le biais important lié à la sélection de type séquentiel. Le choix de la population de base permet également d'expliquer ces valeurs inhabituelles. Les modèles 2 et 3 donnent des estimées légèrement moins élevées pour les héritabilités que le modèle 1 , à cause de la faiblesse des effets maternels. Le modèle 1 permet néanmoins un bon compromis entre simplicité des calculs et qualité de la description.

dinde / paramètre génétique / maximum de vraisemblance restreinte

\section{INTRODUCTION}

Poultry breeding is characterized by large populations subject to few environmental effects (often accounted for in evaluations as a unique contemporary group, ie, hatch effect). This explains why selection index theory has been used successfully for the past few decades, while analysis of (co)variances (ANOVA) type methods were used to estimate genetic and phenotypic correlations.

Despite its simplicity and its properties, selection index theory is open to improvement, most notably because it does not account for possible differences in expected values between contemporary groups and/or generations, or for changes in additive genetic variances due to selection, inbreeding, and preferential matings (Bulmer, 1971). As a result, since Henderson's pioneering work (1973), the methodology of best linear unbiased prediction applied to an animal model (BLUP-AM) has been developed in many livestock species for routine genetic evaluations. This method requires knowledge of variance components in a supposedly unselected and unrelated base population. Yet genetic parameters have to be estimated from available data. Despite the computational difficulty, the method of restricted maximum likelihood (REML) presented by Patterson and Thompson (1971) has been shown to have most desirable properties, mainly because of its ability to correct for bias due to selection (Gianola et al, 1986) .

Poultry breeding companies have only lately come to use these more advanced evaluation methods, certainly because the need to use them seemed less stringent than for other livestock species (Hartmann, 1992). For example, Besbes et al (1992, 1993) recently illustrated their use in selection of laying hens. 
Breeding of meat-type poultry is done under quite different circumstances from those of laying hens, because of the peculiar selection scheme where birds are sequentially measured, evaluated and culled. The bias involved in the last evaluation stages may be considerable when the selection based on the previous step is not accounted for. In such a situation, it is preferable, although often computationally demanding (Ducrocq, 1994), to use a multitrait approach and include all records on which selection is based. Better use of the available information results in greater accuracy and reduces systematic biases in estimates of population genetic parameters and BVs. For example, it may be beneficial to undertake a joint estimation of genetic parameters for reproductive and growth traits in turkeys because 1) reproductive traits are measured on a restricted fraction of the population; 2) there are missing records for some traits, which is the outcome of selection based on body weight; and 3) intense selection on both growth and reproductive traits has been carried out for many generations.

This study aims to estimate genetic parameters of production traits in selected turkey strains using REML methodology with an animal model.

\section{MATERIALS AND METHODS}

\section{Data and description of traits}

This study was based on data from three selected strains of turkeys, referred to as strains A, B and C. Strains A and B are female lines. Strain C is a male line, which produces tom turkeys for matings at the final stage of a crossbreeding scheme. Elementary statistics for each trait are given in table I. Data were provided by Bétina Selection and included four, three, and five generations of records for animals of strains $\mathrm{A}, \mathrm{B}$, and $\mathrm{C}$ respectively. For each strain, the ancestors of the first generation analyzed were known and were, according to theory, considered as the unselected and non-inbred base population.

The traits considered in this analysis were related to growth as well as to egg production and carcass composition. Selected birds were successively weighed, measured for leanness and eventually mated to produce the next generation.

The birds were weighed at 12 and 16 weeks of age. Sex in broilers has often been considered as an environmental effect that could be adequately adjusted for in the evaluation model by a simple multiplicative a priori transformation. Basically, such a data manipulation assumes similar development in both sexes. However, comparisons of early growth and development of both sexes have been carried out in many bird species and sex differences have been found for hormonal and regulatory systems in turkeys (Vasilatos-Younken et al, 1988), as well as for body weight of chick embryos (Burke and Sharp, 1989) and feed and water consumption (Marks, 1985). Moreover, some papers have reported differences in the genetic parameter estimates between sexes in chickens (Merritt, 1966; Morton, 1973) as well as in turkeys (Toelle et al, 1990). Therefore, in order to account for the sexual dimorphism observed in turkeys and thoroughly investigated by Shaklee et al (1952), it was decided to consider weight as a sex-limited trait. As a consequence, four growth traits were analyzed : $\mathrm{BW} 12_{\mathrm{f}}, \mathrm{BW} 16_{\mathrm{f}}, \mathrm{BW} 12_{\mathrm{m}}$, and $\mathrm{BW} 16_{\mathrm{m}}$, where the subscripts $\mathrm{f}$ and $\mathrm{m}$ stand for female and male respectively and $\mathrm{BW}$ for body weight. 
Table I. Elementary statistics for male and female body weights at 12 and 16 weeks of age (BW), ultrasonic backfat thickness (UBT) and Box-Cox transformed egg numbers $\left(\mathrm{EN}^{1 *}\right.$ and $\left.\mathrm{EN2}{ }^{*}\right)$.

\begin{tabular}{|c|c|c|}
\hline Trait & Number of records & Mean $\pm s d$ \\
\hline \multicolumn{3}{|l|}{ Strain A } \\
\hline $\mathrm{BW} 12_{\mathrm{f}(\mathrm{g})}$ & 8050 & $4840 \pm 402$ \\
\hline $\mathrm{BW} 12_{\mathrm{m}(\mathrm{g})}$ & 6789 & $6414 \pm 534$ \\
\hline$B W 16_{f(g)}$ & 8050 & $7053 \pm 531$ \\
\hline $\mathrm{BW} 16_{\mathrm{m}(\mathrm{g})}$ & 6789 & $9917 \pm 715$ \\
\hline UBT (arbitrary units) & 2565 & $60 \pm 11$ \\
\hline $\mathrm{EN} 1^{*}$ & 1868 & $22 \pm 8$ \\
\hline EN2* & 1742 & $26 \pm 10$ \\
\hline \multicolumn{3}{|l|}{ Strain B } \\
\hline$B W 12_{f(g)}$ & 10548 & $4569 \pm 450$ \\
\hline $\mathrm{BW} 12_{\mathrm{m}(\mathrm{g})}$ & 6377 & $6273 \pm 590$ \\
\hline$B W 16_{f(g)}$ & 10548 & $6518 \pm 625$ \\
\hline $\mathrm{BW} 16_{\mathrm{m}(\mathrm{g})}$ & 6377 & $9444 \pm 832$ \\
\hline $\mathrm{EN} 1^{*}$ & 1693 & $25 \pm 9$ \\
\hline $\mathrm{EN}^{*}$ & 1489 & $30 \pm 15$ \\
\hline \multicolumn{3}{|l|}{ Strain $C$} \\
\hline $\mathrm{BW} 12_{\mathrm{f}(\mathrm{g})}$ & 10506 & $7719 \pm 704$ \\
\hline $\mathrm{BW} 12_{\mathrm{m}(\mathrm{g})}$ & 9653 & $9779 \pm 941$ \\
\hline $\mathrm{BW} 16_{\mathrm{f}(\mathrm{g})}$ & 10506 & $11361 \pm 886$ \\
\hline $\mathrm{BW} 16_{\mathrm{m}(\mathrm{g})}$ & 9653 & $15218 \pm 1268$ \\
\hline UBT (arbitrary units) & 4402 & $67 \pm 10$ \\
\hline
\end{tabular}

Strain A: 14839 records, 15874 individuals in the pedigree data set (492 sires; 2258 dams); strain B: 16925 records, 17695 individuals in the pedigree data set (403 sires; 1914 dams); strain C: 20159 records, 20732 individuals in the pedigree data set (432 sires; 2517 dams).

Some birds died during the rearing period; others were eliminated at the weighing times. The causes for removals were diverse and not recorded. Incidences of eliminations were $1,0.3$ and $3 \%$ for females in strains $\mathrm{A}, \mathrm{B}$, and $\mathrm{C}$ respectively. These rates were $0.6,3$ and $6 \%$ for males in the same strains. The higher removal rate in strain $\mathrm{C}$ was likely a result of the intense selection carried out, mainly on weight criteria, as is common in heavy turkey strains. Unfortunately, the early records pertaining to all birds missing at the second weighing were not available. As a result, only records of the birds weighed both at 12 and 16 weeks were included in this study.

The birds were also selected for leanness. For that purpose, ultrasonic backfat thickness (UBT) was measured on the subset of the females remaining after the selection based on body weight. This measure was made to assess subcutaneous fat and is reasonably well correlated $(\rho=0.7)$ with total carcass fat content (Russeil, 1987). It required a well-trained person to detect the right location for the ultrasonic probe, and the plucking of some $2 \mathrm{~cm}^{2}$ of skin. The measuring device was scaled so that it returned the value 100 when applied to a plexiglass tube of given dimensions. 
For this reason, the UBT units are arbitrary. Data pertaining to UBT measures were available for strains $\mathrm{A}$ and $\mathrm{C}$ only.

The turkey hens were placed into cages between 29 and 32 weeks of age and then photostimulated for egg production. Eggs were collected for 25 weeks after the photostimulation. The first egg was laid roughly 3 weeks after the photostimulation. Therefore the effective recording period lasted 22 weeks. Eggs laid during the first three weeks by early turkeys were also included. In order to improve egg production using part-record selection as suggested by Clayton (1962), the total period was split into two halves. The first period (P1), which started with the photostimulation and lasted for 14 weeks, reflected a trait combining sexual maturity and early laying. This period was followed by the second period, P2, which lasted 11 weeks up to the end of the control period, and measured the persistency of lay. There was no overlap between P1 and P2. Both records were affected by broodiness. Broodiness is a heritable trait and early papers have shown that it can be reduced by selection for low incidence (McCartney, 1956) or increasing egg number (Knox and Mardsen, 1954), while, according to Nestor (1972), selection against the days lost from broodiness during the laying period did not result in as great an increase in total egg production as direct selection on egg number. Nevertheless, management techniques are now widely used to reduce the proportion of broody hens in production flocks. In this study, broody turkeys were not disturbed and their records were considered as complete. EN1 and EN2 were the total numbers of eggs collected during P1 and P2 respectively, regardless of their status, eg, hatchable, broken, or shell-defective. Some mortality occurred among the laying turkeys. When death occurred during P2, EN1 was kept while EN2 was discarded. When death occurred during P1, the whole record was regarded as missing.

EN1 and EN2 showed markedly leptokurtic distributions. In order to satisfy the classical hypothesis for describing traits with polygenic inheritance via a linear model with normal error, a power transformation (Box and Cox, 1964) was used. This transformation, and its adaptation to egg number in laying hens, was used by Besbes et al (1992). The transformation has the following form :

$$
g_{\tau}(y)=\left\{\begin{array}{cc}
\frac{y^{\tau}-1}{\tau \dot{y}^{(\tau-1)}} & \text { if } \tau>0 \\
\log (y) & \text { if } \tau=0
\end{array}\right.
$$

where $\dot{y}$ is the geometric mean of the $y$ 's.

This transformation relies on a single parameter $\tau$, empirically chosen, as proposed by Ibe and Hill (1988), to fulfill simultaneously some desirable criteria. The value $\tau$ should first minimize the residual mean of squares of transformed observations described via a classical linear model. The value of $\tau$ is also chosen in order to satisfy, as for as possible, the best fit of regression of half sib performances on that of the individual (ie, the assumption of linearity for the genetic relationship between related animals), the symmetry of the distribution, and the assumption of normality (here, the departure from normality was measured using the ShapiroWilk test). The values of $\tau$ used for EN1 and EN2 were respectively 2.75 and 1.7 in strain A and 2.4 and 1.8 in strain B. There were no records of egg production for the male line $\mathrm{C}$. EN1* and $\mathrm{EN}{ }^{*}$ were the reparametrized variables used in the 


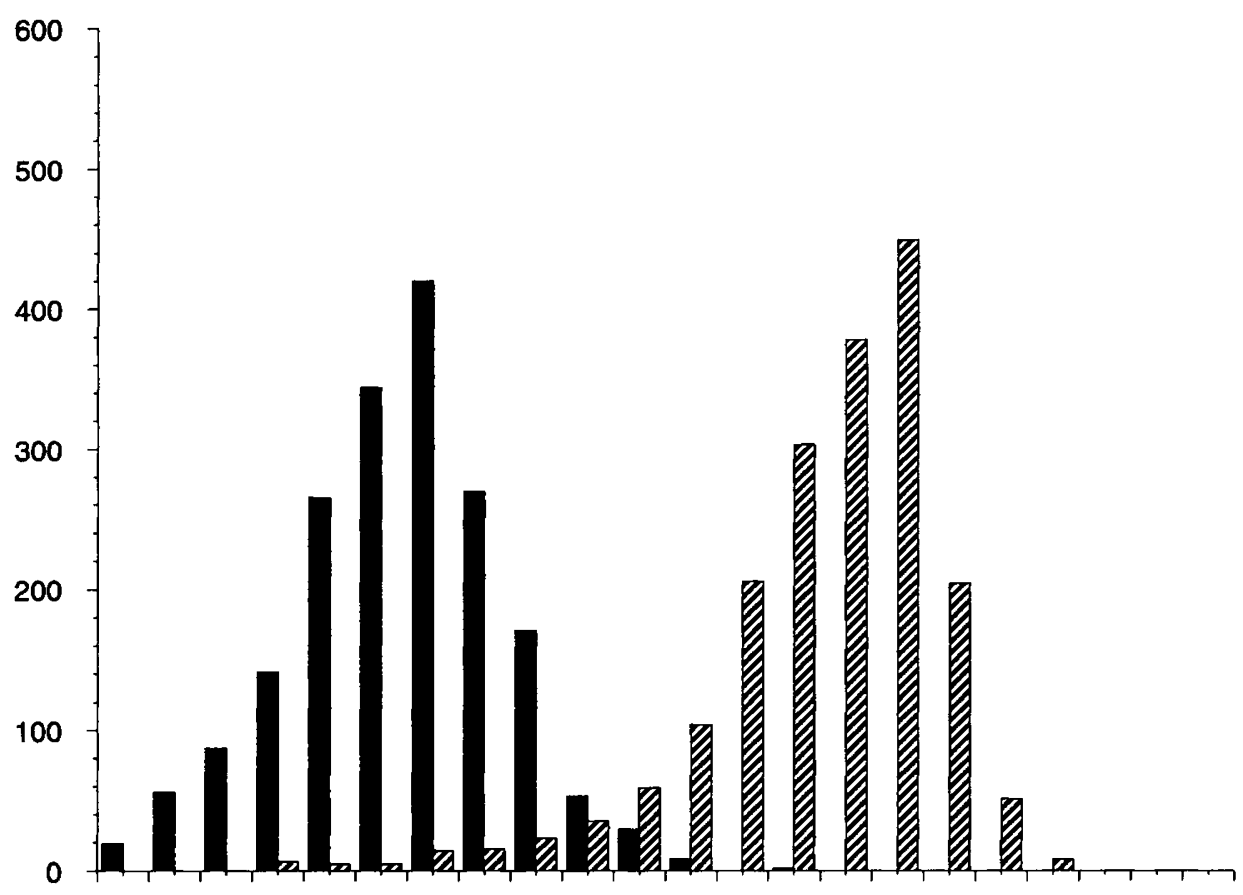

Fig 1. Influence of the Box-Cox transformation on the distribution of egg number in strain A. $\mathbf{~ : ~ t r a n s f o r m e d ~ d a t a ; ~} \mathrm{a}$ : row data.

REML analysis developed below. The distributions of EN1 and EN1* in strain A are shown in figure 1.

\section{Models of analysis}

Variance components were estimated by restricted maximum likelihood applied to an individual animal model.

Koerhuis (1994) performed a derivative-free REML estimation of body weight under an individual animal model for large broiler data sets. As proposed by Meyer (1992a), six different animal models were fitted, ranging from a simple model with animals as the only random effects to the most comprehensive model allowing for both genetic and environmental maternal effects and a genetic covariance between direct and maternal effects. The latter model resulted in the largest log likelihood value.

In the present study, it was desired to perform multivariate analyses because sequential selection invalidates univariate analyses. Unfortunately, the computational burden involved by a multivariate analysis for $t$ traits is far greater than for $t$ univariate analyses. As detailed in table II, the dimension of the mixed-model equations (MME; Henderson, 1973) inflates when additional effects are included. Moreover, a nonzero covariance between direct and maternal genetic effects is likely to considerably increase computing time, because it reduces the sparsity of the MME 
coefficient matrix, so that sparse inversion or factorization in the REML algorithm becomes prohibitive. In addition, whatever the model used, the greater the number of components required for the estimation, the slower the convergence towards stable estimates. Therefore, considering the total amount of information available, it was not possible to estimate all the components pertaining to Meyer's (1992a) complete model in a multivariate analysis. In particular, the genetic covariance between direct and maternal effects was set to zero because it could not be correctly estimated. These are the reasons why three simpler models were studied. Model 1 was a purely direct genetic model, model 2 also allowed also for a dam's environmental effect, while model 3 included a maternal genetic effect in addition to the additive direct genetic effect, assuming a zero covariance between these two effects. In other words, the extra resemblance between full sibs was assumed to have an environmental or genetic origin in models 2 and 3 respectively.

Table II. Comparison of computational requirements for different genetic models when the number of random effects introduced and/or the variance covariance structure of these random effects vary.

\begin{tabular}{lccc}
\hline Model & $\begin{array}{c}\text { Number } \\
\text { of components }\end{array}$ & $\begin{array}{c}\text { Number } \\
\text { of } M M E^{\text {a }}\end{array}$ & $\begin{array}{c}\text { Nonzero } \\
\text { coefficients } \\
\text { in MME }\end{array}$ \\
\hline (1): Additive genetic effect & 46 & 111238 & $3 \times 10^{6}$ \\
(2): (1) + dam's environmental effect & 74 & 158358 & $4 \times 10^{6}$ \\
(3): (1) + maternal genetic effect (zero covariance & 74 & 222356 & $6 \times 10^{6}$ \\
$\quad$ between direct and maternal effect) & 102 & 222356 & $>9 \times 10^{6}$ \\
(4): same as (3) with non-zero covariance & 102 & 269476 & $7 \times 10^{6}$ \\
(5): (3) + dam's environmental effect & 130 & 269476 & $>10^{7}$ \\
(6): (4) + dam's environmental effect & & & \\
\hline
\end{tabular}

${ }^{\text {a }}$ Mixed-model equations.

In the present study, (co)variance components were estimated using the restricted maximum likelihood variances-covariances estimation (REML-VCE) package developed by Groeneveld (1993).

\section{Additive model (model 1)}

Let $N_{i}$ be the number of animals measured on the $i$ th trait. $N$ is the total number of animals included in the analysis. The following linear mixed model, 'model 1', was used:

$$
\boldsymbol{y}_{i}=\boldsymbol{X}_{i}{ }_{i}+\mathbf{Z}_{i} \mathbf{a}_{i}+\mathbf{e}_{i}
$$

where:

$\boldsymbol{y}_{i}\left(N_{i}\right)$ is the vector of $N_{i}$ observations collected for the $i$ th trait;

${ }_{i}\left(f_{i}\right)$ is the vector of fixed effects for the $i$ th trait. $i_{i}$ is a contemporary group (hatch) fixed effect vector pertaining to all traits but UBT. The UBT 
measure depends greatly on the operator's ability. Because different operators might have been involved for the measurement of a given hatch, a combined effect hatch $\times$ operator was chosen for this particular trait;

$\mathbf{a}_{i}(N)$ is the vector of random additive genetic effects for $i$ th trait;

$\boldsymbol{e}_{i}\left(N_{i}\right)$ is the vector of residuals for $i$ th trait;

$\boldsymbol{X}_{i}\left(N_{i}, f_{i}\right)$ and $\boldsymbol{Z}_{i}\left(N_{i}, N\right)$ are known design matrices which connect $\beta_{i}$ and $\mathbf{a}_{i}$ with $\boldsymbol{y}_{i} . \boldsymbol{X}_{i}$ and $\boldsymbol{Z}_{i}$ depend on the trait considered because of the missing values involved in sequential selection and because body weight was treated as a sex-limited trait.

It is assumed that $\boldsymbol{y}_{i}, \mathbf{a}_{i}$, and $\boldsymbol{e}_{i}$ are normally distributed with:

$$
E\left[\begin{array}{l}
\boldsymbol{y}_{i} \\
\mathbf{a}_{i} \\
\boldsymbol{e}_{i}
\end{array}\right]=\left[\begin{array}{cc}
\boldsymbol{X}_{i} & i \\
\mathbf{0} \\
\mathbf{0}
\end{array}\right]
$$

and

$$
\operatorname{Var}\left[\begin{array}{l}
\mathbf{a}_{i} \\
\boldsymbol{e}_{i}
\end{array}\right]=\left[\begin{array}{cc}
\boldsymbol{A} \sigma_{a_{i}}^{2} & \mathbf{0} \\
\mathbf{0} & \boldsymbol{I} \sigma_{e_{i}}^{2}
\end{array}\right]
$$

After reordering the data by trait within animal, let $\mathbf{a}$ and $\mathbf{e}$ be the vectors of additive genetic values and residuals respectively. The complete system is then:

$$
\operatorname{Var}\left[\begin{array}{l}
\mathbf{a} \\
\mathbf{e}
\end{array}\right]=\left[\begin{array}{cc}
\boldsymbol{A} \oplus \boldsymbol{G} & \mathbf{0} \\
\mathbf{0} & \bigoplus_{j=1}^{N} \boldsymbol{R}_{k_{j}}
\end{array}\right]
$$

where $\boldsymbol{A}$ is the known relationship matrix between animals. $\boldsymbol{G}$ is the unknown genetic variance-covariance matrix between traits and $\otimes$ is the Kronecker product.

$\boldsymbol{R}_{k_{j}}$ is the residual variance-covariance matrix pertaining to the $j$ th animal which is subject to the $k_{j}$ th pattern of missing values. If $\boldsymbol{R}$ is the residual variancecovariance matrix among all traits, $\boldsymbol{R}_{k_{j}}$ is obtained by deleting from $\boldsymbol{R}$ the rows and columns corresponding to the missing traits.

\section{Common environmental effect model (model 2)}

The previous model might be open to criticism, especially because it does not account for egg characteristics which are supposed to influence the development of the embryo and the early growth of the bird. Indeed, a large variation among estimates can be found in the literature for turkey growth trait based on sire, dam, or sire plus dam components. Delabrosse et al (1986) reported heritabilities of $0.26\left(h_{s}^{2}\right)$ and $0.80\left(h_{d}^{2}\right)$ for BW at 13 weeks of males from a Bétina female line. These discrepancies most likely resulted from the bias involved in the more intense selection carried out on sires, but also suggest the influence of maternal and/or dominance effects.

As an initial approach, we introduced a common environmental 'hatch $\times$ dam' effect to account for a common effect on all eggs of a given hen. In particular, we expected to account, as much as possible, for the age of the hens, which is known to influence egg weight (Shalev and Pasternak, 1993). In addition, this effect, which is 
common to full-sibs of a hatch (dams being mated to a single sire) partly accounts for dominance effects.

For trait $i$, model 2 is:

$$
\boldsymbol{y}_{i}=\boldsymbol{X}_{i}{ }_{i}+\boldsymbol{Z}_{i} \mathbf{a}_{i}+\boldsymbol{W}_{i} \boldsymbol{p}_{i}+\boldsymbol{e}_{i}
$$

where $\boldsymbol{a}_{i},{ }_{i}, \boldsymbol{e}_{i}, \boldsymbol{X}_{i}$ and $\boldsymbol{Z}_{i}$ are the same as given for model $1 ; \boldsymbol{p}_{i}$, of dimension $N_{p}$, is a random effect common to all the progeny of a hatch from a given dam; and $\boldsymbol{W}_{i}$ is the corresponding design matrix.

Thus we have the following variance-covariance structure for the multivariate analysis, where $\boldsymbol{P}$ is the variance-covariance matrix for the environmental effect $\boldsymbol{p}$ :

$$
\operatorname{Var}\left[\begin{array}{c}
\mathbf{a} \\
\boldsymbol{p} \\
\boldsymbol{e}
\end{array}\right]=\left[\begin{array}{ccc}
\boldsymbol{A} \otimes \boldsymbol{G} & \mathbf{0} & \mathbf{0} \\
\mathbf{0} & \boldsymbol{I}_{N_{P}} \otimes \boldsymbol{P} & \mathbf{0} \\
\mathbf{0} & \mathbf{0} & \bigoplus_{j=1}^{N} \boldsymbol{R}_{k_{j}}
\end{array}\right]
$$

\section{Maternal genetic effect model (model 3)}

Considering that the influence of the egg on the development of the embryo may have more of a genetic than an environmental origin (egg weight is a trait with an average heritability of 0.50 (Buss, 1989)), we have introduced a maternal genetic effect to account for the additional genetic relationships between dams.

For the $i$ th trait, model 3 is:

$$
\boldsymbol{y}_{i}=\boldsymbol{X}_{i}{ }_{i}+\mathbf{Z}_{i} \mathbf{a}_{i}+\boldsymbol{K}_{i} \mathbf{m}_{i}+\boldsymbol{e}_{i}
$$

where $\boldsymbol{m}_{i}\left(N_{M}\right)$ is the vector of maternal effects, and $\boldsymbol{K}_{i}$ is the corresponding design matrix.

In the multivariate analysis, the variance-covariance structure is:

$$
\operatorname{Var}\left[\begin{array}{c}
\mathbf{a} \\
\mathbf{m} \\
\boldsymbol{e}
\end{array}\right]\left[\begin{array}{ccc}
\boldsymbol{A} \otimes \boldsymbol{G} & \mathbf{0} & \mathbf{0} \\
\mathbf{0} & \boldsymbol{A} \otimes \boldsymbol{M} & \mathbf{0} \\
\mathbf{0} & \mathbf{0} & \bigoplus_{j=1}^{N} \boldsymbol{R}_{k_{j}}
\end{array}\right]
$$

where $\boldsymbol{M}$ is the variance-covariance matrix of maternal effects $\mathbf{m}$.

Unfortunately, computational costs prohibited an analysis for all traits simultaneously under this model. We suspected, however, that the influence of a maternal genetic effect was greater for traits measured early in life. Therefore this model was used in a four-trait study where only male and female body weights were included, regardless of UBT or egg numbers which were to be measured at a later age during the selection cycle. To ensure that the partial analysis was reliable, estimates obtained for BW under model 1 in a four-trait analysis were first compared with those obtained in an analysis including all selected traits. For both analyses, the genetic parameters were nearly identical. 


\section{Sexual dimorphism}

Body weight was considered as a sex-influenced trait to account for sexual dimorphism. Inheritance of sex differences for turkey body weight has been investigated by Shaklee et al (1952) and the variation between dams with regard to body weight differences of their progeny was found to be significant. Advantage was taken of the REML estimates from the previous analyses to derive heritabilities of sexual dimorphism. Details of the derivation are in the Appendix.

\section{RESULTS}

Estimates of additive genetic parameters for each strain are in tables III-V. The size of the maternal effects was small (in percent of total variance, it was less than 5, 2 , and $8 \%$ for strains A, B and C respectively). The use of models 2 and 3 resulted in a reduction of the direct heritabilities for all of the traits but UBT in strain C.

Table III. Estimates of genetic parameters for strain A for male and female body weight (BW) at 12 and 16 weeks of age, ultrasonic backfact thickness (UBT), and Box-Cox transformed egg numbers $\left(\mathrm{EN} 1^{*}\right.$ and $\left.\mathrm{EN} 2^{*}\right)$.

\begin{tabular}{|c|c|c|c|c|c|c|c|}
\hline & $B W 12_{f}$ & $B W 12_{m}$ & $B W 16_{f}$ & $B W 16_{m}$ & $U B T$ & $E N 1^{*}$ & $E N \mathscr{2}^{*}$ \\
\hline \multirow[t]{3}{*}{$\mathrm{BW} 12_{\mathrm{f}}$} & 0.595 & 0.896 & 0.937 & 0.885 & 0.382 & -0.482 & -0.387 \\
\hline & 0.545 & 0.932 & 0.937 & 0.932 & 0.443 & -0.527 & -0.453 \\
\hline & 0.527 & 0.923 & 0.935 & 0.906 & - & - & - \\
\hline \multirow[t]{3}{*}{$\mathrm{BW} 12_{\mathrm{m}}$} & & 0.549 & 0.759 & 0.934 & 0.403 & -0.449 & -0.459 \\
\hline & & 0.447 & 0.798 & 0.942 & 0.379 & -0.492 & -0.461 \\
\hline & & 0.462 & 0.787 & 0.936 & - & - & - \\
\hline \multirow[t]{3}{*}{$\mathrm{BW} 16_{\mathrm{f}}$} & & & 0.615 & 0.829 & 0.403 & -0.512 & -0.458 \\
\hline & 0.846 & & 0.575 & 0.878 & 0.465 & -0.572 & -0.544 \\
\hline & & & 0.564 & 0.853 & - & - & - \\
\hline \multirow[t]{3}{*}{$\mathrm{BW} 16_{\mathrm{m}}$} & & & & 0.596 & 0.343 & -0.372 & -0.384 \\
\hline & & 0.851 & & 0.467 & 0.355 & -0.427 & -0.474 \\
\hline & & & & 0.525 & - & - & - \\
\hline \multirow[t]{3}{*}{ UBT } & & & & & 0.474 & -0.117 & -0.083 \\
\hline & 0.341 & & 0.390 & & 0.388 & -0.182 & -0.040 \\
\hline & & & & & - & - & - \\
\hline \multirow[t]{3}{*}{ EN1* } & & & & & & 0.351 & 0.813 \\
\hline & -0.220 & & -0.217 & & -0.156 & 0.329 & 0.883 \\
\hline & & & & & - & - & - \\
\hline \multirow[t]{2}{*}{ EN2* } & & & & & & & 0.218 \\
\hline & -0.179 & & -0.153 & & -0.123 & 0.422 & 0.180 \\
\hline
\end{tabular}

Heritabilities are given on the diagonal, genetic correlations above diagonal, phenotypic correlations below diagonal. For each trait, read on the $i$ th line estimates pertaining to model $i$. Model 1 is a purely additive model. Model 2 allows for the dam's environmental effect. Model 3 is the same as model 1 with a maternal genetic effect in addition (zero covariance is assumed between direct and maternal effects). 
Table IV. Estimates of genetic parameters for strain B for male and female body weight (BW) at 12 and 16 weeks of age, and Box-Cox transformed egg numbers (EN1* and EN2*).

\begin{tabular}{|c|c|c|c|c|c|c|}
\hline & $B W 12_{f}$ & $B W 12_{m}$ & $B W 16_{f}$ & $B W 16_{m}$ & $E N 1^{*}$ & $E N 2^{*}$ \\
\hline $\mathrm{BW} 12_{\mathrm{f}}$ & $\begin{array}{l}0.710 \\
0.705 \\
0.698\end{array}$ & $\begin{array}{l}0.922 \\
0.929 \\
0.936\end{array}$ & $\begin{array}{l}0.964 \\
0.967 \\
0.973\end{array}$ & $\begin{array}{l}0.936 \\
0.937 \\
0.948\end{array}$ & $\begin{array}{c}-0.119 \\
-0.109 \\
-\end{array}$ & $\begin{array}{c}-0.384 \\
-0.468 \\
-\end{array}$ \\
\hline $\mathrm{BW} 12_{\mathrm{m}}$ & & $\begin{array}{l}0.637 \\
0.615 \\
0.617\end{array}$ & $\begin{array}{l}0.855 \\
0.869 \\
0.887\end{array}$ & $\begin{array}{l}0.946 \\
0.951 \\
0.957\end{array}$ & $\begin{array}{c}-0.152 \\
-0.147 \\
-\end{array}$ & $\begin{array}{c}-0.276 \\
-0.385 \\
-\end{array}$ \\
\hline $\mathrm{BW} 16_{\mathrm{f}}$ & 0.908 & & $\begin{array}{l}0.768 \\
0.769 \\
0.767\end{array}$ & $\begin{array}{l}0.944 \\
0.947 \\
0.955\end{array}$ & $\begin{array}{c}-0.110 \\
-0.105 \\
-\end{array}$ & $\begin{array}{c}-0.378 \\
-0.453 \\
-\end{array}$ \\
\hline $\mathrm{BW} 16_{\mathrm{m}}$ & & 0.896 & & $\begin{array}{l}0.681 \\
0.673 \\
0.671\end{array}$ & $\begin{array}{c}-0.170 \\
-0.163 \\
-\end{array}$ & $\begin{array}{c}-0.310 \\
-0.414 \\
-\end{array}$ \\
\hline EN1* & -0.050 & & -0.045 & & $\begin{array}{c}0.336 \\
0.317 \\
-\end{array}$ & $\begin{array}{c}0.694 \\
0.752 \\
-\end{array}$ \\
\hline EN2* & -0.180 & & -0.171 & & -0.479 & $\begin{array}{c}0.211 \\
0.198 \\
-\end{array}$ \\
\hline
\end{tabular}

Heritabilities are given on the diagonal, genetic correlations above diagonal, phenotypic correlations below diagonal. For each trait, read on the $i$ th line estimates pertaining to model $i$. Model 1 is a purely additive model. Model 2 allows for the dam's environmental effect. Model 3 is the same as model 1 with a maternal genetic effect in addition (zero covariance is assumed between direct and maternal effects).

The maximum decrease observed in strain A (see table III) was $22 \%$ for $B W 16_{m}$ ( 0.47 with model 2 vs 0.60 with model 1 ). In strain B (see table IV) the maximum reduction was $7 \%$, for EN2* $(0.20$ with model 2 vs 0.21 with model 1$)$. In strain $\mathrm{C}$ (see table V), it was $19 \%$, for BW12 ( 0.35 with model 3 vs 0.43 with model 1 ).

Below, unless indicated otherwise, numerical illustrations are given using estimates obtained under model 1 , as they refer to the model likely to be used in routine genetic evaluations.

Heritability estimates for body weight were large. They reached 0.77 for $\mathrm{BW} 16_{\mathrm{f}}$ in strain B. Female weights were more heritable than male ones, especially in line $\mathrm{C}$ (0.51 vs 0.43 for BW12, and 0.50 vs 0.37 for BW16). Sampling variance of the estimates was not available, so that we cannot assert that the genetic correlations between male and female body weights were significantly different from unity. Still, in both lines $\mathrm{A}$ and $\mathrm{C}$, whatever the model applied, BW16 $\mathrm{m}$ was genetically more correlated with $\mathrm{BW} 12_{\mathrm{f}}(0.88$ in line $\mathrm{A}$ vs 0.82 in line $\mathrm{C})$ than with $\mathrm{BW16} \mathrm{f}_{\mathrm{f}}(0.83$ in line $\mathrm{A}$ vs 0.78 in line $\mathrm{C}$ ). In addition, in these strains the genetic correlations between weights were higher within a sex than between sexes. 
Table V. Estimates of genetic parameters for strain $\mathrm{C}$ for male and female body weight (BW) at 12 and 16 weeks of age and ultrasonic backfat thickness (UBT).

\begin{tabular}{|c|c|c|c|c|c|}
\hline & $B W 12_{f}$ & $B W 12_{m}$ & $B W 16_{f}$ & $B W 16_{m}$ & $U B T$ \\
\hline$B W 12_{f}$ & $\begin{array}{l}0.513 \\
0.485 \\
0.470\end{array}$ & $\begin{array}{l}0.886 \\
0.919 \\
0.911\end{array}$ & $\begin{array}{l}0.922 \\
0.915 \\
0.912\end{array}$ & $\begin{array}{l}0.820 \\
0.845 \\
0.838\end{array}$ & $\begin{array}{c}0.157 \\
0.033 \\
-\end{array}$ \\
\hline $\mathrm{BW} 12_{\mathrm{m}}$ & & $\begin{array}{l}0.432 \\
0.373 \\
0.354\end{array}$ & $\begin{array}{l}0.735 \\
0.763 \\
0.751\end{array}$ & $\begin{array}{l}0.924 \\
0.928 \\
0.924\end{array}$ & $\begin{array}{c}0.233 \\
0.115 \\
-\end{array}$ \\
\hline $\mathrm{BW} 16_{\mathrm{f}}$ & 0.777 & & $\begin{array}{l}0.502 \\
0.473 \\
0.458\end{array}$ & $\begin{array}{l}0.783 \\
0.810 \\
0.801\end{array}$ & $\begin{array}{r}0.097 \\
-0.059 \\
-\end{array}$ \\
\hline $\mathrm{BW} 16_{\mathrm{m}}$ & & 0.759 & & $\begin{array}{l}0.369 \\
0.320 \\
0.307\end{array}$ & $\begin{array}{c}0.214 \\
0.093 \\
-\end{array}$ \\
\hline UBT & 0.213 & & 0.194 & & $\begin{array}{c}0.345 \\
0.364 \\
-\end{array}$ \\
\hline
\end{tabular}

Heritabilities are given on the diagonal, genetic correlations above diagonal, phenotypic correlations below diagonal. For each trait, read on the $i$ th line estimates pertaining to model $i$. Model 1 is a purely additive model. Model 2 allows for the dam's environmental effect. Model 3 is the same as model 1 with a maternal genetic effect in addition (zero covariance is assumed between direct and maternal effects).

Surprisingly, line B differed from the others in weight traits. Though phenotypic differences were obvious between males and females (see table I) in this strain, 'late' traits were as strongly genetically correlated $\left(0.94\right.$ between $B W 16_{f}$ and $\left.B W 16_{m}\right)$ as 'early' traits $\left(0.92\right.$ for $\mathrm{BW} 12_{\mathrm{f}}$ and $\left.\mathrm{BW} 12_{\mathrm{f}}\right)$.

Heritabilities of sexual dimorphism are reported in Table VI. These were relatively low. At a given age, the highest estimates were obtained with model $1(0.23$, 0.16 and 0.14 for $\Delta \mathrm{BW} 16$ in strains $\mathrm{A}, \mathrm{B}$ and $\mathrm{C}$ respectively), and the lowest with model $3(0.17,0.14$ and 0.11$)$. Differences between male and female body weights were slightly more heritable at later ages in strains $\mathrm{A}$ and $\mathrm{C}$.

UBT was positively correlated with body weight in strains A and C. Use of model 2 resulted in lower values for these correlations in strain $\mathrm{C}$ where they were, in general, close to zero. Genetic correlations were slightly negative between EN1* and UBT and near zero with EN2*.

Heritabilities of egg production traits were moderate and similar in strains A and B. EN2*, which was more subject to environmental variation, was less heritable than EN1*. However, the genetic correlation between EN1* and EN2* was high in strain A as well as in strain B. EN1* was negatively genetically correlated with body weight in strain A and especially with BW16 $\mathrm{f}_{\mathrm{f}}(-0.512)$, though the phenotypic correlation between $\mathrm{EN1}^{*}$ and body weight was only -0.22 . In strain $\mathrm{B}$, however, the genetic correlation between $\mathrm{EN}^{*}$ and body weight was lower in magnitude, 
Table VI. Estimates of heritability of body weight sex difference $(\Delta \mathrm{BW})$ at 12 and 16 weeks of age derived under three different genetic models.

\begin{tabular}{lccc}
\hline Strain & Model & $\Delta B W 12$ & $\Delta B W 16$ \\
\hline A & 1 & 0.137 & 0.229 \\
& 2 & 0.127 & 0.220 \\
B & 3 & 0.083 & 0.167 \\
& 1 & 0.173 & 0.163 \\
& 2 & 0.156 & 0.156 \\
C & 3 & 0.143 & 0.139 \\
& 1 & 0.100 & 0.142 \\
& 2 & 0.064 & 0.110 \\
& 3 & 0.062 & 0.107 \\
\hline
\end{tabular}

Model 1 is a purely additive model. Model 2 allows for the dam's environmental effect. Model 3 is the same as model 1 with a maternal genetic effect in addition (zero covariance is assumed between direct and maternal effects).

whereas in both strains $\mathrm{A}$ and $\mathrm{B}$ correlations between $\mathrm{EN} 2^{*}$ and $\mathrm{BW}$ were clearly negative.

\section{DISCUSSION}

\section{Methodology}

REML has become the method of choice for estimating genetic parameters because of its desirable statistical and genetic properties, eg, Harville (1977), Kennedy et al (1988), Robinson (1991). This method accounts for the effect of selection on estimated parameters, provided that all the information related to selection is included in the analysis. In our study, this requirement was not entirely fulfilled because, as stated above, only birds weighed at both 12 and 16 weeks were available for the analysis. The loss of information pertaining to birds removed between 12 and 16 weeks was likely to have introduced a small bias because the surviving birds were not randomly sampled from the initial population as they were indirectly selected for against locomotor troubles or other diseases. In addition, the base population, in which genetic parameters are estimated by the REML method, is supposed to be non-inbred, unrelated and unselected. It is important not to deviate too far from these requirements because, according to van der Werf and Thompson (1992), incorrect assumptions about the base animals generally affect the resulting estimates more than ignoring relationships in later generations. The rate of increase of inbreeding was calculated and appeared to be less than 0.008 per generation. This is an indication that the first assumption may be reasonably well satisfied. Previous selective breeding, however, carried out in some strains for more than 20 generations, was not taken into consideration. Many generations of selection are likely to introduce an important decrease in the genetic variances (Bulmer, 1971), especially at the beginning of the selection process. Unfortunately, the information 
relative to the first years of selection was not available in our case. It was not possible to include in our analyses all the birds involved in the selection as required by the REML theory. Adding any intermediate ancestor generation did not, therefore, seem relevant because this would have considerably increased computing time, without fully taking into account the Bulmer effect.

Another assumption made in this study remains open to criticism. For computational simplicity, a zero covariance between direct genetic and maternal effects was assumed. This is probably not true. The consequences of this assumption deserve further consideration.

Because of some cross-substitution effects in the partitioning of the total variance, setting the direct-maternal covariance $\left(\sigma_{\mathrm{AM}}\right)$ to zero leads to a possible underestimation of $\sigma_{\mathrm{A}}^{2}$ and $\sigma_{\mathrm{M}}^{2}$ if $\sigma_{\mathrm{AM}}$ is negative, or to an overestimation of these components if $\sigma_{\mathrm{AM}}$ is positive. Koerhuis (1994) found that direct maternal genetic correlation for juvenile body weight of broilers was highly negative. Meyer (1992b) pointed out also that the sampling variance of estimates increases when estimating $\sigma_{\mathrm{AM}}$. Besides, data structure in the selected turkey strains was not favorable to an accurate estimation of $\sigma_{\mathrm{AM}}$ because of treatment of body weights as sex-limited traits. In the present study, the magnitude of the maternal variance was small in model 3. It might have been underestimated, but accounting for $\sigma_{\mathrm{AM}}$ would have caused a loss of precision that would have impaired the reliability of the estimates.

\section{Genetic parameters}

As a result of the age at measurement, sex, strain, and method of estimation, considerable variation is found in the literature concerning estimates of heritabilities and genetic correlations for both growth and reproductive traits. According to Buss (1989), the most reliable estimates for body weight heritabilities range from 0.23 to 0.71 . Our estimates ranged from 0.30 to 0.77 , with most estimates above 0.50 , and are therefore in the upper part of the Buss range. They are also higher than those obtained by Delabrosse et al (1986) using older estimation methods. Mielenz et al (1994) also reported high values of heritabilities for BW and egg weight in laying hens. They performed multitrait REML analyses and compared their results with those obtained with Henderson's method 3. The largest discrepancies between these estimates (and the highest values for REML estimates) were found when many consecutive generations were considered. In the literature, there are many reports of experiments where the REML estimates depend on the number of generations included in the analysis, especially when the generations do not overlap. Meyer and Hill (1991) analyzed a 23 generation selection experiment on mice. Starting with a base population, and then adding various numbers of subsequent generations, they found a large variability among the heritability estimates of the selected trait (average food intake). They concluded that a change in genetic variances that could not be correctly taken into account in an infinitesimal model had occurred during the course of the experiment. Variations were lower for an unselected trait (6 week BW) but were not negligible either. In the present study, where selection was on all traits and generations did not overlap, the selected lines differed in their origin, in the number of previous selected generations, and in their mean level of performance. It appears that the higher the generation numbers used in the analysis, the lower the heritability estimates for body weight; the number of generations analyzed should 
not however, be viewed as a discriminatory factor under the infinitesimal model. Other differences between strains must be considered. The number of generations known to have undergone previous selection (for which data were for the most part not available) ranges from five for strain B to more than 30 for strain $\mathrm{C}$. The number of individuals per generation also differed among the strains. Strain B has been selected for the shortest time, with the largest size per generation. The heritability estimates are therefore found to be very high. Strain $\mathrm{C}$ had undergone selection for body weight alone for many years, and more recently for the UBT values of females. It is thus understandable why we obtain lower estimates for heritability of body weight in strain $\mathrm{C}$. This would probably not have been true if we had analyzed all the data on which selection had been based in strain $\mathrm{C}$. Becker et al (1994) reported a genetic correlation of 0.91 between sexes for BW at 24 weeks in turkeys. In this study, growth traits were highly correlated within sexes and, to a lesser extent, between sexes at a given age. Strains $\mathrm{A}$ and $\mathrm{C}$ showed some similarities: the largest genetic correlation between sexes was obtained between $\mathrm{BW} 12_{\mathrm{m}}$ and BW12 , ie, between 'early' traits. However, this correlation seemed to be different from unity. The results suggested that $\mathrm{BW} 16_{\mathrm{m}}$ was more closely related to $\mathrm{BW} 12_{\mathrm{f}}$ than to $\mathrm{BW} 16_{\mathrm{f}}$. Female development being more precocious, growing females appear more mature than males at a given age. Here, this hypothesis was somewhat supported by the slightly higher influence of maternal effects on male traits than on female traits. An accurate study of the respective growth curves of males and females and, in particular, the timing of the weighing periods with regard to some critical points on the growth curve, may permit the verification of this assumption. Discrepancies between male and female estimates might have resulted from different growth metabolisms, but other causes, such as incidences of leg disorders, might be responsible as well. Moderate estimates obtained for heritabilities of sexual dimorphism indicate that selection aiming at reducing or increasing this difference may be possible. This was reported by Korkman (1957) and Schmidt (1993) who altered sex-differences for BW by selection in populations of mice. According to Shaklee et al (1952), attempts to develop strains of turkeys in which males and females have approximately the same age at market weight are feasible. The practical value of such a selection, however, has to be assessed. The most efficient way to modify this dimorphism is to consider BW as a sexlimited trait and to use weighing coefficients with different signs for these traits in the derivation of aggregate genotype. Computation of the heritability of sexual dimorphism is interesting since it concisely displays the possibilities of selection to modify this dimorphism. Besides, it provides a synthetic parameter that allows easy comparisons between strains and species.

The use of the Box-Cox transformation of egg numbers resulted in a better agreement with the assumptions of a normal distribution of a trait. Hence a better estimation of correlations involving egg numbers was expected. Nestor (1980a) stated that the association between egg production and BW is slightly negative during the first generations of selection for either increased BW or increased egg production. McCartney et al (1968), in close agreement with Cook et al (1962), found an average correlation of $-0.15 \pm 0.1$ between BW at 24 weeks. and 84-day egg production. Arthur and Abplanalp (1975) reported an average value of +0.03 for this correlation. After a few generations of selection for either increased BW or 
egg production, however, this association becomes strongly negative (Nestor, 1977, $1980 \mathrm{~b}$ ). In our study, correlations between EN and BW were negative in both lines. They were much more unfavorable in strain A. The magnitude of this antagonism between $\mathrm{BW}$ and reproductive ability seems to be a result of the selection carried out on BW, while differences found between strains $\mathrm{A}$ and $\mathrm{B}$, in the estimates of correlations, might be due to past selection and to the different genetic origin of the lines. A long-lasting selection process may modify the genetic correlations between traits affected by selection (Villanueva and Kennedy, 1990). Hence discrepancies observed in estimates of genetic parameters between lines A and B, especially for the large negative correlation between $\mathrm{EN}^{*}$ and growth traits, might be at least partly explained by differences in their previous selection history.

Heritabilities of UBT were moderate in both strains. The estimated correlations showed a positive link between weights and UBT, which was stronger in the A line than in the $\mathrm{C}$ line. On average, heavier birds were fatter. The correlation with egg numbers was slightly negative, in agreement with a review by Mallard and Douaire (1988) who concluded that leanness seemed to be an asset for the reproductive ability of birds.

Another problem is the reliability of the different models in a routine evaluation procedure of breeding values. Henderson (1975) showed algebraically that ignoring some random effects in genetic evaluation may still result in unbiased estimates and predictions, but with increases in the sampling variances compared with evaluation under a complete model. Roehe and Kennedy (1993) evaluated the loss of selection response caused by using model 1 vs a model including a maternal effect. Neglecting maternal effects reduced the accuracy of the evaluation of direct effects only slightly, and caused an increasing overestimation of genetic trend of direct effect over 10 years. Therefore, younger animals were more frequently selected than older animals. When generations do not overlap, this kind of bias does not dramatically affect selection decisions. A package performing a routine BLUP evaluation of breeding values under model 3 within reasonable computing costs would be helpful as it takes advantage of the estimates of maternal effects.

\section{CONCLUSION}

Reliable estimates of genetic parameters are essential to take full advantage of the properties of BLUP predictions of breeding values. The genetic parameters estimated in the present study are likely to be more adequate for the strains than previous estimates, especially because they account for the sequential selection carried out within generations in turkey breeding. In addition, the Box-Cox transformation of egg numbers results in a better fit of the assumptions for analysis of egg production traits. The REML procedure used to estimate population parameters is, however, computationally very demanding and limits the possible sophistication of the model used. A simple direct additive model was compared with models accounting for a permanent environmental effect from the dam or for a genetic maternal effect. Heritability estimates decreased when accounting for maternal or environmental effects but remained high, while their correlations were not dramatically altered. It can therefore be assumed that the MT-BLUP evaluation under model 1 did in fact permit an acceptable evaluation and selection of current 
candidates, but one must be aware that it leads to an overestimation of the actual genetic progress.

\section{ACKNOWLEDGMENTS}

We are indebted to the staff of Bétina Sélection for collecting the data. We are also grateful to D Boichard, whose help was greatly appreciated when getting started with VCE.

\section{REFERENCES}

Arthur JA, Ablanalp H (1975) Linear estimates of heritability and genetic correlation for egg production, body weight, conformation and egg weight of turkeys. Poult Sci 54, 11-23

Becker WA, Sinha SP, Bogyo TP (1964) The quantitative genetic relationship of sexual dimorphism of birds. Genetics 50, 2355 (Abstr.)

Besbes B, Ducrocq V, Foulley JL, Protais M, Tavernier A, Tixier-Boichard M, Beaumont C (1992) Estimation of genetic parameters of egg production traits of laying hens by restricted maximum likelihood applied to a multiple-trait reduced animal model. Genet Sel Evol 24, 539-552

Besbes B, Ducrocq V, Foulley JL, Protais M, Tavernier A, Tixier-Boichard M, Beaumont C (1993) Box-Cox transformation of egg production traits of laying hens to improve genetic parameter estimation and breeding evaluation. Livest Prod Sci 33, 313-326

Box GPE, Cox DR (1964) An analysis of transformations. $J$ R Stat Soc B 26, 211-243.

Bulmer M G (1971) The effect of selection on genetic variability. Am Nat 105, 201-211.

Burke WH, Sharp PJ (1989) Sex differences in body weight of chick embryos. Poult Sci $68,805-810$

Buss EG (1989) Genetics of turkeys: economic traits. World's Poult Sci J 45, 125-167

Cook RE, Blow WL, Cockerham CC, Glazener EXW (1962) Improvement of reproductive traits and body measurements of turkeys. Poult Sci 41, 556-563

Clayton GA (1962) Estimates of some parameters concerning fecundity in turkeys. Br Poult Sci 3, 3-7

Delabrosse Y, Douaire M, Mallard J (1986) Les paramètres génétiques de la composition corporelle chez la dinde. In: 7th European Poultry Conference, Paris, 24-28 aout 1986, WPSA branche française, vol II, 171-175

Ducrocq V (1994) Multiple trait prediction: principles and problems. In: 5th World Congr Genet Appl Livest Prod, Guelph, 7-12 August 1994, University of Guelph, Guelph, vol XVIII, 5WCGALP Organizing Commitee, 455-462

Gianola D, Foulley JL, Fernando RL (1986) Prediction of breeding values when variances are not known. Genet Sel Evol 18, 475-484

Groeneveld E (1993) REML VCE-a multivariate multimodel restricted maximum likelihood (co)variance component estimation package. In: Proc EC Seminar on Application of Mixed Linear Models in the Prediction of Genetic Merit in Pigs (E Groeneveld, ed), 83-102

Hartmann W (1992) Evaluation of the potentials of new scientific developments for commercial poultry breeding. World's Poult Sci J 48, 17-27

Harville DA (1977) Maximum likelihood approaches to variance component estimation and to related problems. J Am Stat Assoc 72, 320-338

Henderson CR (1973) Sire evaluation and genetic trends. In: Proceedings of the Animal Breeding and Genetics Symposium in honor of Dr JL Lush, Blacksburg, VA, August 1973. American Society of Animal Science, Champaign, IL, 10-41 
Henderson CR (1975) Comparison of alternative sire evaluation methods. J Anim Sci 41, 760-770

Ibe SN, Hill WG (1988) Transformation of poultry egg production data to improve normality, homoscedasticity and linearity of genotypic regression. J Anim Breed Genet $105,231-241$

Kennedy BW, Schaeffer LR, Sorensen DA (1988) Genetic properties of animal models. $J$ Dairy Sci 71, 17-26

Knox CW, Mardsen SJ (1954) Breeding for increased egg production in Beltsville Small White turkeys. Poult Sci 33, 443-447

Koerhuis ANM (1994) Derivative-free REML under an individual animal model for large data sets on broilers. In: 5th World Congr Genet Appl Livest Prod, Guelph, 7-12 August 1994, University of Guelph, Guelph, vol XVIII, 5WCGALP Organizing Committee, $422-425$

Korkman N (1957) Selection with regard to the sex difference of body weight in mice. Hereditas 43, 665-678

Mallard J, Douaire M (1988) Strategies of selection for leanness in meat production. In: Leanness in Domestic Birds (B Leclercq, CC Whitehead, eds), Butterworths \& Co Pub Ltd, INRA, 3-23

Marks HL (1985) Sexual dimorphism in early feed and water intake of broilers. Poult Sci 64, 425-428

McCartney MG (1956) Reproductive performance in broody and nonbroody turkeys. Poult Sci 35, 763-765

McCartney MG, Nestor KE, Harvey WR (1968) Genetics of growth and reproduction in the turkey. 2. Selection for increased body weight and egg production. Poult Sci 47, 981-990

Meyer K (1992a) Variance components due to direct and maternal effects for growth traits of Australian beef cattle. Livest Prod Sci 31, 179-204

Meyer K (1992b) Bias and sampling covariances of estimates of variance components due to maternal effects. Genet Sel Evol 24, 487-509

Meyer K, Hill WG (1991) Mixed-model analysis of a selection experiment for food intake in mice. Genet Res 57, 71-81

Merritt ES (1966) Estimates by sex of genetic parameters for body weight and skeletal dimensions in a random bred strain of meat type fowl. Poult Sci 45, 118-125

Mielenz N, Groeneveld E, Muller J, Spilke J (1994) Simultaneous estimation of variances and covariances using REML and Henderson 3 in a selected population of White Leghorns. Br Poult Sci 35, 669-676

Morton JR (1973) Analysis of gene action in the control of body weight in the chicken. Heredity 31, 165-180

Nestor KE (1972) Broodiness, intensity of lay and total egg production of turkeys. Poult Sci $51,86-92$

Nestor KE (1977) Genetics of growth and reproduction in the turkey. 5. Selection for increased body weight alone and in combination with increased egg production. Poult Sci $56,337-347$

Nestor KE (1980a) Genetics of growth and reproduction in the turkey. 7. Relationship of total egg production, intensity of lay, broodiness and body weight. Poult Sci 59, $1385-1394$

Nestor KE (1980b) Genetics of growth and reproduction in the turkey. 8. Influence of a management change on response to selection for increased egg production. Poult Sci 59, 1961-1969

Patterson HD, Thompson R (1971) Recovery of inter-block information when block sizes are unequal. Biometrika 58, 545-554 
Robinson GK (1991) That BLUP is a good thing: the estimation of random effects. Stat Sci $6,15-51$

Roehe R, Kennedy W (1993) The influence of maternal effects on accuracy of evaluation of litter size in swine. J Anim Sci 71, 2353-2364

Russeil $\mathrm{P}(1987)$ Estimation in vivo de la composition corporelle chez la dinde. $\mathrm{PhD}$ thesis, University of Rennes, France

Schmidt AT (1993) Divergent selection for sexual dimorphism in mice. In: 44th Annual Meeting of the EAAP, Aahrus, 16-19 August 1993, Mette Roneklint Sørensen, Commission of Animal Genetics, paper G6.6

Shaklee WE, Knox CW, Mardsen SJ (1952) Inheritance of sex difference of body weight in turkeys. Poult Sci 31, 822-825

Shalev BA, Pasternak H (1993) Increment of egg weight with hen age in various commercial avian species. Br Poult Sci 34, 915-924

Toelle VD, Havenstein BG, Nestor KE, Bacon WL (1990) Estimates of genetic parameters in turkeys. 3. Sexual dimorphism and its application in selection procedures. Poult Sci $69,1634-1643$

van der Werf JHJ, Thompson R (1992) Variance decomposition in the estimation of genetic variance with selected data. J Anim Sci 70, 2975-2985

Vasilitos-Younken R, Bacon WL, Nestor KE (1988) Relationship of plasma growth hormone to growth within and between turkey lines selected for differential growth rates. Poult Sci 67, 826-834

Villanueva B, Kennedy BW (1990) Effect of selection on genetic parameters of correlated traits. Theor Appl Genet 80, 746-752

\section{APPENDIX}

\section{Heritability of sexual dimorphism}

Assume $\triangle \mathrm{BW}$ is the difference 'male body weight minus female body weight' at a given age. The additive genetic variance of $\triangle B W$ is:

$$
\sigma_{a_{(\Delta \mathrm{BW})}}^{2}=\sigma_{a_{(1)}}^{2}+\sigma_{a_{(2)}}^{2}-2 \sigma_{a_{(1,2)}}^{2}
$$

where the subscript 1 stands for male and 2 for female.

Assuming that covariances between direct, residual and maternal effects are zero, the total variance of $\triangle \mathrm{BW}$ is:

$\sigma_{T_{(\Delta \mathrm{BW})}}^{2}=\sigma_{a_{(1)}}^{2}+\sigma_{a_{(2)}}^{2}+\sigma_{m_{(1)}}^{2}+\sigma_{m_{(2)}}^{2}+\sigma_{e_{(1)}}^{2}+\sigma_{e_{(2)}}^{2}-2 \sigma_{a_{(1,2)}}^{2}-2 \sigma_{m_{(1,2)}}^{2}-2 \sigma_{e_{(1,2)}}^{2}$ where $\sigma_{k_{(i)}}^{2}, k=a, m, e ; i=1,2$ is the direct additive $(k=a)$, maternal $(k=m)$ or residual $(k=e)$ variance for male $(i=1)$ or female $(i=2) \mathrm{BW}$; and $\sigma_{k_{(1,2)}}^{2}, k=$ $a, m, e$ is the direct additive $(k=a)$, maternal $(k=m)$, or residual $(k=e)$ covariance between male and female BW. $\sigma_{e_{(1,2)}^{2}}^{2}$ is zero because no animal exhibits both traits.

So the heritability for sexual dimorphism can be expressed as:

$$
h_{(\Delta \mathrm{BW})}^{2}=\frac{\sigma_{a_{(\mathrm{m})}}^{2}+\sigma_{a_{(\mathrm{f})}}^{2}-2 \sigma_{a_{(\mathrm{m}, \mathrm{f})}}^{2}}{\sigma_{a_{(\mathrm{m})}}^{2}+\sigma_{a_{(\mathrm{f})}}^{2}+\sigma_{m_{(\mathrm{m})}}^{2}+\sigma_{m_{(\mathrm{f})}}^{2}+\sigma_{e_{(\mathrm{m})}}^{2}+\sigma_{e_{(\mathrm{f})}}^{2}-2 \sigma_{a_{(\mathrm{m}, \mathrm{f})}}^{2}-2 \sigma_{m_{(\mathrm{m}, \mathrm{f})}}^{2}}
$$

